https://doi.org/10.48009/1_iis_2006_167-174

\title{
ASSESSMENT OF COMPUTER SELF-EFFICACY: INTEGRATING LAPTOPS ACROSS THE SCHOOL OF BUSINESS CURRICULUM
}

\author{
Monica J. Parzinger, St. Mary's University, mparzinger@stmartytx.edu \\ Thomas E. Reeves, St. Mary's University, treeves@ stmarytx.edu \\ Orion J. Welch, St. Mary's University, owelch@stmarytx.edu
}

\begin{abstract}
Many universities now require students to use laptop computers in their curriculum. It is important that these institutions evaluate and measure their progress in achieving purported goals. One approach is the assessment of computer self-efficacy at various educational phases. Our study focuses on the initial data analysis gathered from business majors at varying stages of education. Our analysis reflects that while the experience levels of specific software packages have significantly improved, there has not been a significant increase in student levels of computer self-efficacy.
\end{abstract}

Keywords: Computer Self-efficacy, Computer Experience, Laptops, Cluster Analysis

\section{INTRODUCTION}

Strategic planning processes at a growing number of universities recognize that an educated person must be capable of using a variety of Information Technology (IT) tools. The trend of embedding information technologies in the education process is not unique. A 2001 Chronicle of Higher Education study reported approximately 55\% of universities required students to have computers. That number is increasing each year.

It is important that universities evaluate and measure their progress and success in achieving their goal of producing information technology enlightened graduates. While some aspects of this process is discipline specific, computer self-efficacy, which measures the confidence the student has developed in his or her ability to learn new information technologies, is not. Higher self-efficacy leads to greater use of technology and better performance [8].

Our research into computer self-efficacy centers around St. Mary's University, a private, catholic school located in San Antonio, Texas. Students in all university programs are expected to graduate with proficiencies in information technologies relevant to their respective disciplines. The university has committed considerable resources in facilities, infrastructure and training over the past five years to support this initiative. Included in the effort is the laptop program. Each undergraduate student receives a laptop computer when enrolling at St. Mary's. The laptops are replaced every two years to maintain currency and compatibility. In addition, each freshman must take a series of computer proficiency exams as part of their enrollment process. If deficiencies are identified, the students are required to successfully complete up to 3 credit hours of computer modules during their freshman year.

The discussion that follows focuses on the initial data analysis gathered from business majors in the Bill Greehey School of Business at varying stages of education. Assessing the degree of computer selfefficacy at various educational phases provides some insight into the effectiveness of the integrated laptop program.

\section{UNDERLYING THEORY}

The following section first defines self-efficacy as based on the work of A. Bandura [1]. This concept is then applied to the field of computers. A brief review of selected literature is presented to establish the foundation for our research.

Self-efficacy refers to a belief in one's capabilities to successfully perform a specific task [1]. It is an important concept because of its outcomes. These outcomes may fall into one of four categories: (1) Influencing the situations and activities that individuals choose, (2) Influencing the extent to which individuals will exert the effort required to overcome obstacles and persist, (3) Influencing individuals' feelings of stress and anxiety, and (4) Predicting performance and coping behavior [6].

As academicians, we can see how important it is for students to reach high levels of self-efficacy in order to perform at acceptable levels in their educational endeavors [3].

Computer self-efficacy may be defined as an individual's perceptions of his or her ability to use a computer when necessary to perform a job task [2]. 
This does not refer to the capability of using a specific software feature. It describes how successful people feel they can be at tasks that require the use of computers. This in turn may affect whether or not the technology will actually be used. [7].

There are numerous factors that can influence computer self-efficacy and ultimately computer utilization and job performance. One of these factors is past accomplishments. Social Cognitive Theory, based on the work of Bandura, suggests that one's own experience provides the most accurate and reliable source of efficacy information [4]. We therefore focused our research on the relationship between computer experience and computer selfefficacy. We propose the following:

Due to the required integration of computer technology in the university curriculum, computer self-efficacy will increase for students between freshman status to junior status, and again, from junior status to senior status.

\section{METHODOLOGY}

The following section describes the development of the survey instrument used in the research, the data gathering process, and the results.

\section{Computer Experience and Self-Efficacy}

Various computer self-efficacy measures have been developed. The questionnaire used in this study was based upon that developed by Compeau \& Higgins [2]. The eleven items in the survey attempt to measure the ability to use an unfamiliar piece of software. Students were asked to rate their level of confidence on a 5-point Likert scale from "Not at all Confident" to "Totally Confident." The computer self-efficacy items are as follows:

Q1: if there was someone giving me step by step instructions

Q2: if there was no one around to tell me what to do as I go

Q3: if I had never used a package like it before

Q4: if I had only the software manuals for reference

Q5: if I had seen someone else using it before trying it myself

Q6: if I could call someone for help if I got stuck

Q7: if someone else had helped me get started

Q8: if I had a lot of time to complete the job for which the software was provided

Q9: if I had just the built-in help facility for assistance

Q10: if someone showed me how to do it first
Q11: if I had used similar packages before this one to do the same job

In addition to the computer self-efficacy items, questions were posed addressing students' experience levels with eight computer applications. Students were asked to rate their level of experience on a scale from 1 (no experience) to 5 (extensive experience) for the following computer applications:

- Word Processing - Project Management

- Spread Sheet

- E-Mail

- Presentation

- Web Development

- Database

- Programming

Depth of exposure with some of the software packages is influenced by student major, but some level of student exposure occurs within the required curriculum for each student.

\section{Data Collection}

The survey instrument was distributed to multiple sections of three levels of required business classes during the Fall 2005 semester. Respondents were students in a freshman level Introduction to Business course, a junior level Management of Information Systems course and a senior level Business Capstone course. All classes assessed were required of all business majors. Participation was voluntary and uncompensated. Only 4 responses were incomplete and deemed unusable.

\section{Results}

In order to determine if computer self-efficacy increased during the typical college progression of courses, t-values were calculated to measure the differences between the levels of courses. In addition, an unsupervised clustering technique was used to identify similar characteristics for categorizing the results.

Table 1 presents the mean self-reported experience level of the eight computer applications used in the study. Only two applications, word processing and spreadsheets, follow the progression of increased experience level over the three periods covered.

Using SPSS, t-values and associated p-values were calculated to determine significance in differences between Seniors and Freshmen and Seniors and Juniors. Table 2 shows the t-values reflecting differences in computer experience levels. An alpha of .05 (critical t-values are -1.96 and 1.96) is used for 
the significance level. Significant values are indicated for word processing, spreadsheets, database, and project management. Web development is also significant at the same level but in the opposite direction than might be expected.

Table 1. Mean Experience Level with Applications

\begin{tabular}{|c|c|c|c|}
\hline Application & FR & JR & SR \\
\hline $\mathbf{N}=$ & 56 & 36 & 47 \\
\hline Word Processing & 4.41 & 4.50 & 4.68 \\
\hline Spreadsheet & 3.46 & 3.50 & 3.87 \\
\hline Presentation & 3.84 & 3.78 & 4.17 \\
\hline Database & 2.78 & 2.50 & 3.06 \\
\hline Project Management & 2.55 & 2.36 & 2.92 \\
\hline E-Mail & 4.75 & 4.81 & 4.79 \\
\hline Web Development & 2.84 & 2.06 & 2.23 \\
\hline Programming & 2.25 & 1.67 & 1.98 \\
\hline Overall & 3.41 & 3.33 & 3.74 \\
\hline
\end{tabular}

Table 2. t-Values of Mean Experience Level

\begin{tabular}{|l|c|c|c|c|}
\hline & \multicolumn{2}{|c|}{$\begin{array}{c}\text { Between } \\
\text { Seniors and } \\
\text { Freshmen }\end{array}$} & \multicolumn{2}{c|}{$\begin{array}{c}\text { Between } \\
\text { Seniors and } \\
\text { Juniors }\end{array}$} \\
\hline Application & $\mathbf{t}$ & $\mathbf{p}$ & $\mathbf{t}$ & $\mathbf{p}$ \\
\hline $\begin{array}{l}\text { Word } \\
\text { Processing }\end{array}$ & $2.10^{*}$ & .038 & 1.43 & .157 \\
\hline Spreadsheet & $2.25^{*}$ & .027 & 1.7 & .094 \\
\hline Presentation & 1.81 & .074 & 1.83 & .072 \\
\hline Database & 1.64 & .105 & $2.54^{*}$ & .014 \\
\hline $\begin{array}{l}\text { Project } \\
\text { Management }\end{array}$ & 1.66 & .099 & $2.22^{*}$ & .030 \\
\hline E-Mail & .39 & .696 & -.20 & .839 \\
\hline $\begin{array}{l}\text { Web } \\
\text { Development }\end{array}$ & $-3.19^{*}$ & .002 & .71 & .478 \\
\hline Programming & 1.46 & .146 & 1.52 & .133 \\
\hline Overall & 1.48 & .144 & 1.55 & .138 \\
\hline
\end{tabular}

$*$ Significant at alpha $=.05$

The mean of the eleven items measuring computer self-efficacy were calculated for each of the three groups under analysis. Refer to Table 3. It was expected that the means would progressively increase over the three periods under investigation.
Table 3, Means of Computer Self-efficacy by Level

\begin{tabular}{|l|c|c|c|}
\hline \multicolumn{1}{|c|}{ Item } & Freshmen & Juniors & Seniors \\
\hline \multicolumn{1}{|c|}{$\mathbf{N}=$} & $\mathbf{5 6}$ & $\mathbf{3 6}$ & $\mathbf{4 7}$ \\
\hline Q1 & 4.61 & 4.55 & 4.57 \\
\hline Q2 & 2.95 & 2.47 & 2.64 \\
\hline Q3 & 2.38 & 2.28 & 2.47 \\
\hline Q4 & 3.38 & 3.06 & 3.09 \\
\hline Q5 & 3.47 & 3.39 & 3.30 \\
\hline Q6 & 3.79 & 3.83 & 3.98 \\
\hline Q7 & 3.95 & 3.86 & 3.89 \\
\hline Q8 & 4.02 & 3.70 & 3.96 \\
\hline Q9 & 3.48 & 3.06 & 3.40 \\
\hline Q10 & 4.42 & 4.31 & 4.28 \\
\hline Q11 & 4.32 & 4.17 & 4.11 \\
\hline Overall & 3.70 & 3.51 & 3.61 \\
\hline
\end{tabular}

The t-values of the mean computer self-efficacy measures between seniors and freshmen, however, did not indicate any significant increase or decrease in the students' confidence to use a computer when necessary to perform a job task. The same holds true for Juniors and Seniors. See Table 4.

Table 4. $t$-Values of Mean Computer Self-efficacy

\begin{tabular}{|c|r|r|r|r|}
\hline & \multicolumn{2}{|c|}{$\begin{array}{c}\text { Between Seniors } \\
\text { and Freshmen }\end{array}$} & \multicolumn{2}{c|}{$\begin{array}{c}\text { Between Seniors } \\
\text { and Juniors }\end{array}$} \\
\hline Item & \multicolumn{1}{|c|}{ t } & \multicolumn{1}{|c|}{$\mathbf{p}$} & \multicolumn{1}{c|}{ t } & \multicolumn{1}{c|}{$\mathbf{p}$} \\
\hline Q1 & -.23 & .814 & .30 & .764 \\
\hline Q2 & -1.53 & .130 & .67 & .503 \\
\hline Q3 & .49 & .624 & .87 & .385 \\
\hline Q4 & -1.53 & .129 & .13 & .898 \\
\hline Q5 & -.91 & .368 & -43 & .670 \\
\hline Q6 & 1.08 & .284 & .82 & .416 \\
\hline Q7 & -.29 & .769 & .16 & .870 \\
\hline Q8 & -.25 & .807 & 1.46 & .149 \\
\hline Q9 & -.41 & .684 & 1.51 & .135 \\
\hline Q10 & -.73 & .470 & -.15 & .881 \\
\hline Q11 & -1.26 & .210 & -.31 & .756 \\
\hline Overall & -0.43 & .682 & 0.38 & .70 \\
\hline
\end{tabular}

In summary, the statistical analysis reflects that while the experience levels of specific software packages have significantly improved, there has not been a significant increase in student levels of computer self-efficacy as would be expected. This analysis does not support our proposition that, due to the required integration of computer technology in the university curriculum, computer self-efficacy will increase for students between freshman status to junior status, and again, from junior status to senior status. 


\section{Unsupervised Clustering Methodology}

Unsupervised clustering is a data mining technique that builds models without first predefining classes or categories. A primary goal of unsupervised clustering is to discover which instances or cases to include in each cluster. Data instances are grouped together based on a similarity scheme defined by the clustering system rather than the researcher. However, the meaning of the formed clusters must be evaluated and determined by the researcher.

Many unsupervised clustering systems require the user to provide an initial best estimate about the total number of clusters in the data. Other clustering systems use an algorithm in an attempt to determine a best number of clusters. In our research, the latter approach was used to group instances into clusters of significant interest.

The data mining process was performed using the iDA software package, a Microsoft Excel add-on.
The iDA package uses examples from the data in order to learn and categorize or cluster cases without making any assumptions about the data. When learning is unsupervised, several optimizing heuristic evaluation functions are used to cluster input data into naturally occurring groups [5].

\section{Results of Unsupervised Clustering}

The data instances for the experience with applications and the assessment of the self-efficiency measures were analyzed for data clusters. The unsupervised clustering used all nine of the applications in the evaluation of experience (word processing, spreadsheet, presentation, database, project management, email, web development and programming). The eleven items used to measure computer self-efficacy were also used. Two data clusters were produced. The first cluster is identified as Cluster A and the second as Cluster B. Refer to Table 5.

Table 5. Results of the Unsupervised Clustering

\begin{tabular}{|l|c|c|c|c|}
\hline \multicolumn{1}{|c|}{ Cluster } & A & B & C & D \\
\hline Instances & 98 & 41 & 56 & 26 \\
\hline Q1 & $81 \%=5$ & & $82 \%=5$ & \\
\hline Q2 & & & $54 \%=3$ & \\
\hline Q4 & & & & $56 \%=4$ \\
\hline Q6 & & & & \\
\hline Q7 & & $51 \%=3$ & $54 \%=4$ & $62 \%=3$ \\
\hline Q8 & $67 \%=5$ & $54 \%=3$ & $64 \%=5$ & \\
\hline Q10 & $54 \%=5$ & & & \\
\hline Q11 & & & & \\
\hline & $68 \%=5$ & & & \\
\hline Word Processing & $89 \%=5$ & & & \\
\hline Email & & $71 \%=1$ & & \\
\hline Web Development & & & & \\
\hline Programming & & & & \\
\hline Spreadsheet & & & & \\
\hline & & & & \\
\hline Seniors & & & & \\
\hline
\end{tabular}

Students falling into Cluster A feel that if they had someone giving them instructions or had previously seen the application done before, they could complete the task with total confidence. Whereas, Cluster B members feel that, even if they had someone help them get started and if they had a lot of time to complete the task, they could complete the task with only a moderate degree of confidence.

A second unrestricted cluster analysis was performed using only juniors and seniors. This clustering used experience levels with word processing, spreadsheet, presentation, database and project management as well as the 11 computer self-efficiency items. Programming, web development, and email were eliminated from the analysis because the t-tests suggested no significant differences or a negative difference in experience levels between Freshmen and Seniors. Two data clusters were produced. The first cluster is identified as Cluster $\mathrm{C}$ and the second as Cluster D. 
Cluster C contains members with high levels of selfefficacy represented by step-by-step instruction independence in completing the task even if no one was around. The cluster also included above moderate levels of self-efficacy for successful completion of the task if there was call support and ample time was given for task completion. Cluster D contains members with lower levels of self-efficacy even when ample time is given for task completion. This group also reflects low experience levels for spreadsheet, web development and programming applications.

\section{CONCLUSIONS}

This paper presents an analysis of computer selfefficacy based on computer experience as students progressed through an integrated laptop business curriculum. The study found that while the students reported a statistically significant increase in experience with most of the software packages used in the curriculum, the traditional statistical analysis did not indicate significant increases in computer self-efficacy. This argues against the relationship we proposed. There is no evidence to indicate that as students progress through their university programs utilizing laptops, the experience they gain will result in greater computer self-efficacy. Our discussion includes the results of unrestricted cluster analysis to detect underlying patterns associated with the data. The results of this analysis indicate the curriculum had produced higher computer self-efficacy patterns in some of the items used to measure this construct. However, the overall results suggest a weakness in the current approach to enhancing student performance via information technology.

The use of unrestricted clustering provides greater insight into our statistical results. Students belonging to the cluster associated with higher computer selfefficacy were highly confident in using software whenever they (1) had step-by-step instruction, (2) had observed another person using the software, or (3) were using software similar to other packages. Additionally, the clustering technique results indicate seniors were more likely to be associated with the higher computer self-efficacy category if they had not only those three conditions listed above, but also (1) had available someone to call when they needed assistance or (2) were under no time constraints. This does suggest that as a student progresses through the business curriculum, a higher level of computer selfefficacy is acquired.

Of concern, however, is the fact that the self-efficacy items associated with learning and applying new software or technologies without help from software manuals or help facilities are not associated with the higher self-efficacy clusters. Another interesting observation was that none of the software package experience items that were found to be significant in the t-tests, with the exception of word processing, were associated with the higher self-efficacy clusters. This finding leads to questions surrounding the impact of experience on computer self-efficacy and our training context.

This study did not develop measures for the training context, a variable recognized in the original model as influencing computer self-efficacy. Nevertheless, based on the items identified in the unrestricted cluster analysis, we can begin to question our teaching techniques for laptop usage. Students in this study are comfortable with the techniques they use in the classroom (step-by-step instruction, observing, similar software). Higher levels of computer selfefficacy, however, appear to depend on a greater amount of independent learning. Less structure and more ambiguity in computer related assignments may actually be more beneficial in the long-run.

Our research has its limitations. We have only a cross section of our business students. A longitudinal study that tracks individual students over several years of course work would add rigor to our study. This may also help to explain the self-reported means of Freshmen computer experience being higher than those of upper class students.

In summary, the results of our research did not support what we expected. The curriculum, as it exists, is not encouraging students to become more confident in their ability to use software when they only have limited assistance other than the software help menus and the manuals. College graduates need to develop this confidence in preparation for the professional work environment. Development of courses with embedded technology exercises that limit interaction with the instructors may lead to greater confidence and improved performance in students' careers.

\section{REFERENCES}

1. Bandura, A. (1986). Social foundation of thought and action: A social cognitive_theory. Englewood Cliffs, NJ: Prentice-Hall.

2. Compeau, D. R. \& Higgins, C. A. (1995). Computer self-efficacy: development of a measure and initial test. MIS Quarterly, June, $189-211$. 
3. Gist, M. E. \& Mitchell, T. R. (1992). Selfefficacy: A theoretical analysis of its determinants and malleability. Academy of Management Review, 17(2), 183 - 211.

4. Hasan, B. \& Reithel, B. J. (1998). Performance in Computer Training: Identifying Critical Factors. Proceedings of the annual meeting of the Decision Sciences Institute, Las Vegas, NV, Nov. 21-24.

5. Roiger, R. J. \& Geatz, M. W. (2003). Data Mining A Tutorial-Based Primer, Addison Wesley, Boston.
6. Saks, A. M. (1994). A Psychological Process Investigation for the Effects of Recruitment Source and Organization Information on Job Survival. Journal of Organizational Behavior, Vol. 15, 225 -44.

7. Smith, Sheila M, (Report). http://www.orsa.org/2001/smith.pdf.

8. Smith, S. M (2002). The role of social cognitive career theory in information technology based academic performance. Information Technology, Learning, and Performance Journal, 20(2), 1-10. 